\title{
AS TECNOLOGIAS DA INFORMAÇÃO E COMUNICAÇÃO E 0 USO WHATSAPP: AS POSIÇÕES DOS PROFESSORES DE CIÊNCIAS E BIOLOGIA.
}

\author{
THE INFORMATION AND COMMUNICATION TECHNOLOGIES AND THE USE \\ WHATSAPP: THE POSITIONS OF SCIENCE AND BIOLOGY TEACHERS.
}

Camila Cunha ${ }^{1}$, Alana Freitas dos Santos ${ }^{2}$, Maria do Socorro Andrade dos Santos ${ }^{3}$

Recebido: outubro/2018 Aprovado: novembro/2020

\begin{abstract}
Resumo: Ao passo que a sociedade se transforma e incorpora as tecnologias digitais, surge a necessidade de modificar também a educação. Para que ocorram práticas pedagógicas inovadoras, é necessário de antemão que eles estejam dispostos a aprender a lidar e trabalhar a favor dessas tecnologias. Serão discutidos neste artigo dados de natureza qualitativa e quantitativa de pesquisas empíricas que nos permitiram compreender a posição dos professores diante das TICs e do Whatsapp. Os resultados indicam que os professores depositam grande esperança nas TICs sobretudo para deixar o ensino mais dinâmico e atrativo. Alguns professores as consideram como um recurso, enquanto que outros indicam que as TICs são uma metodologia de ensino. O Whatsapp aparece a tecnologia mais utilizada pelos professores, sendo as TICs utilizadas para viabilizar o ensino de todos os conteúdos de ciências e biologia, mas em especial àqueles que necessitam de maior abstração, como Citologia e Microbiologia. As experiências dos professores mostram as potencialidades e momentos em que a inserção do Whatsapp se efetiva com fins educativos.
\end{abstract}

Palavras-chave: ensino de ciências, professores, TICs

\begin{abstract}
As society transforms and incorporates digital technologies, there is a need to change education as well. In order for innovative pedagogical practices to occur, it is necessary beforehand that they be willing to learn to cope and work in favor of these technologies. We will discuss in this article qualitative and quantitative data of empirical research that allowed us to understand the position of teachers in the face of ICTs and Whatsapp. The results indicate that teachers place great hope on ICTs especially to make education more dynamic and attractive. Some teachers consider them as a resource, while others indicate that ICTs are a teaching methodology. Whatsapp appears as the technology most used by teachers, and ICTs are used to enable the teaching of all contents of science and biology, but especially to those who need more abstraction, such as Cytology and Microbiology. The experiences of teachers show the potentialities and moments in which the insertion of Whatsapp is effective for educational purposes.
\end{abstract}

Keywords: teaching, science education, TICs.

\section{Introdução}

As discussões acerca de como as Tecnologias da Informação e Comunicação (TICs) são usadas na educação vêm ganhando ênfase nas publicações acadêmicas. Para os dispositivos móveis, o campo de estudo conhecido como Mobile Learning (M-learning) já acumula pesquisas

https://orcid.org/0000-0001-8279-4219 - Universidade Federal de Sergipe. Doutoranda no Programa de Pós-graduação em Ensino, Filosofia e História das Ciências (UFBA/UEFS), Salvador, Bahia, Brasil. Rua Dr. Edgar de Barros, n. 7, Edf. Agulhas Negras 202, Amaralina, 41900-420 - Salvador, Bahia, Brasil. E-mail: cunhacamila17@gmail.com.

2 (iD) https://orcid.org/0000-0002-0078-4672- Faculdades Integradas de Sergipe (FISE). Tobias Barreto, Sergipe, Brasil. Rua Dr. Adolfo Viana De Castro, n. 155, Centro, 48330-000, Rio Real, Bahia, Brasil.E-mail: alanafreitas060@gmail.com.

3 (iD https://orcid.org/0000-0002-1853-5076 - Faculdades Integradas de Sergipe (FISE). Tobias Barreto, Sergipe, Brasil. Rua Antônio Moreira Caldas, n. 579, Centro, 48475-000, Itapicuru, Bahia, Brasil. E-mail: ms5551454@gmail.com. 
significativas na área educacional e apresenta-se como uma área do conhecimento em crescimento.

Contudo, iniciativas efetivas em sala ainda são tímidas e pontuais, encontrando diversas dificuldades para se concretizarem no ensino de Ciências e Biologia. Dessa forma, partilhamos alguns questionamentos: Como as TICs se inserem no contexto escolar? Os professores se mostram favoráveis ou desfavoráveis ao uso das TICs em sala de aula? A utilização de aplicativos de comunicação, como o WhatsApp, podem ajudar no trabalho docente? De que forma ele pode ser utilizado como um recurso inovador no ensino de Ciências e Biologia? Quais as experiências dos professores possuem com o uso do WhatsApp para fins educacionais?

A partir desses questionamentos buscamos compreender as TICs enquanto um recurso didático e mais especificamente o WhatsApp enquanto ferramenta auxiliar para as aulas e inovação pedagógica, contribuindo para uma comunicação mais efetiva e reforço dos laços afetivos entre professores e alunos. Nossa ideia é discutir sobre como ele pode favorecer o ensino, sobretudo a partir da opinião daqueles que lidam no dia a dia com a realidade escolar: o professor.

\section{As TICs e o ensino de ciências e biologia}

As relações entre professores e alunos, imersos num contexto global e tecnológico, vêm se modificado e permitem novos espaços de educação além do presencial. Pierre (1999 p. 95) afirma que "a perspectiva da digitalização geral das informações provavelmente torna o ciberespaço o principal canal de comunicação e suporte de memória da humanidade a partir do início do próximo século." Esta digitalização está bem próxima das pessoas e não gera mais estranhamento, sobretudo para os "imigrantes digitais", tornando o ciberespaço um espaço aberto de comunicação.

No que se refere ao acesso à informação, tudo se tornou mais dinâmico e rápido graças à internet. Pode-se ao longo de uma aula, tirar uma dúvida sobre determinado conceito, termo ou até mesmo uma curiosidade acessando rapidamente o Google nos Smartphones. Para Alencar et al. (2015, p. 789), "o significativo aumento do uso das tecnologias móveis na educação, na interatividade e o estreitamento de relações entre aluno, professor e a escola, vem se tornando a saída para muitos problemas de comunicação".

Ao conjunto de tecnologias que intercedem a comunicação e informação, dá-se o nome de Tecnologias da Informação e Comunicação (TICS). Ao passo que a sociedade se transforma e incorpora as tecnologias, surge a necessidade de modificar também a educação. Vianna e Araújo (2006, p. 137) afirmam que "quem está em sala de aula hoje não pode fechar os olhos para o uso da informática. A educação se modifica, e temos que nos valer daquilo que a sociedade fornece: um arsenal de novas tecnologias".

É grande o desafio de apropriação das inovações tecnológicas que permitam novos modos de ensinar/aprender, através de outras formas de comunicação e de um novo espaço de interação humana, e que têm chamado a atenção de muitos pesquisadores das ciências educacionais. Para Ribeiro et al. (2007, p. 2) "os recursos tecnológicos disponíveis, hoje, 
diminuem as dificuldades existentes pela distância física entre alunos e professores. A tecnologia da informática permite criar um ambiente virtual em que alunos e professores sintam-se próximos [...]".

No que se refere à educação básica, a presença das TICs já é sentida nas salas, mesmo que muitas das vezes de maneira incipiente e pouco compreendida pelos professores, que usualmente as negam em suas aulas. Os estudos de Batista e Barcelos (2013) apontam os celulares como um dos principais motivos de distração entre alunos, sendo, portanto, uma das razões para a sua proibição em sala de aula.

Por outro lado, Vasconcelos e Nascimento (2015) indicam que as TICs não podem ser vistas como uma nova salvação para a educação que há muito se encontra em crise, mas que por detrás de sua implementação nos espaços educativos reside a necessidade de reestruturação profunda dos pressupostos educativos. Assim, ainda se faz necessário pensar como a educação é concebida por aqueles que a constroem, visto que as TICs sozinhas não têm o poder de mudar pressupostos educacionais arraigados na cultura escolar. Autores como Martinho e Pombo (2009, p. 528) reiteram essa postura, ao afirmar que as TICs "valorizam, ainda, os processos de compreensão de conceitos e fenômenos diversos, [...]. Contudo, o entusiasmo e a esperança que se deposita nas tecnologias, não podem ser tomados, por si só, como o elixir para todos os males de que a escola procede". Nesse sentido, as TICs podem ser entendidas como um recurso didático que pode auxiliar o professor em seu ensino, seja qual for o método e corrente pedagógica assumida por ele.

Considerando a árdua tarefa de lecionar, umas das dificuldades que os professores enfrentam é a de lidar com recursos didáticos diversos. Para Souza (2007, p. 111) recurso didático "é todo material utilizado como auxílio no ensino-aprendizagem do conteúdo proposto para ser aplicado pelo professor a seus alunos". Podemos citar como exemplos de recursos didáticos, a lousa, modelos como os utilizados para estudo de anatomia humana, um recurso audiovisual como o Datashow, filmes e músicas, dentre tantos outros.

Muitas das vezes a falta de estrutura física e financeira das escolas prejudicam a oferta destes recursos aos professores, que acabam limitados ao uso do livro didático. Em alguns casos, a escola possui estrutura adequada, mas seus professores não foram formados para lidar com alguns destes recursos, especialmente os mais tecnológicos, como a internet, aplicativos educacionais, plataformas de compartilhamento de materiais, lousa digital e Datashow. Quartiero (1999) afirmava em meados dos anos 90 que estávamos em um estágio bastante rudimentar no que se refere ao conhecimento informacional, em especial ao emprego dessas ferramentas para fins educacionais. Quase 17 anos depois, em algumas escolas, sobretudo as públicas e de cidades interioranas, essa realidade parece bastante atual.

Artigos mais recentes como o de Leite (2014), já apresentam teorias da aprendizagem considerando uma filosofia geral para educação na era digital. Tais teorias consideram também as revoluções ocorridas no campo da informática, como a ascensão dos Smartphones e a crescente produção de conteúdo por parte dos usuários da internet (LEITE, 2014). A evolução tecnológica e as discussões acadêmicas já indicam que a escola não pode ignorar mais a existência desses recursos de acesso à informação e que ela não é mais o espaço privilegiado de 
acesso ao conhecimento (LEITE, 2014), mesmo que ainda seja uma instituição respaldada pela sociedade.

O ensino de Ciências e Biologia apresenta conteúdos complexos, com fenômenos, etapas e processos naturais, muitas das vezes microscópicos. Imaginar um mundo além do que é visto à olho nu, por exemplo, parece mais complicado sem o auxílio de imagens, representações e esquemas. Recursos de áudio e vídeo já são utilizadas por professores para suprir essa dificuldade em entender as representações científicas dos fenômenos biológicos. Documentários, filmes e vídeos fazem parte da rotina e do planejamento de muitos professores da educação básica, indicando que as TICs já se fazem presente e são aliadas na hora de ensinar.

Diante disto, compreendemos as TICs enquanto um recurso didático valioso para o ensino de Ciências e Biologia, o que não significa considerá-las como único recurso, mas como uma das inúmeras ferramentas para viabilizar um ensino mais dinâmico e interativo. Ademais, a ampliação no acesso às TICs traz consigo um desafio a mais para a educação: o de ensinar os alunos a selecionarem e avaliarem de maneira crítica as informações às quais ele tem acesso. Habilidade extremante necessária diante das informações falseadas e produzidas de maneira irresponsável no ambiente virtual. Esta reflexão não será aprofundada aqui, entretanto, faz-se pertinente para perceber que as TICs, trazem uma possibilidade de renovação metodológica ao ensino, mas que sua inserção nos espaços escolares deve ser planejada e orientada com fins educacionais.

\section{M-Learning e Whatsapp no Ensino}

Dentre as possibilidades de uso das TICs na educação, vêm se destacado o uso dos aparelhos móveis como os Tablets e Smartphones. O conceito de Mobile Learning (M-learning) surge para abarcar esse campo específico de investigação e busca analisar como os dispositivos móveis podem colaborar para a aprendizagem (BATISTA; BARCELOS, 2013). De maneira mais ampla o termo M-Learning pode designar também as aprendizagens que ocorrem "quando o estudante não está em um local estático e estipulado, ou no momento em que a aprendizagem acontece quando o estudante 'tira' vantagem das oportunidades de aprendizagem oferecidas por tecnologias móveis" (LEITE, 2014, p. 59).

O uso do M-Learning na educação apresenta algumas vantagens em relação ao ensino tradicional, visto que é possível aproveitar as potencialidades de dispositivos móveis que a maioria dos alunos já possui. Martinho e Pombo (2009) indicam ainda que as TICs possibilitam para o ensino uma alteração nos papéis de professores e alunos, colocando estes últimos numa posição mais ativa, redefinindo pedagogias de ensino. É possível assim listar outras vantagens do M-Learning, tais como: a ampliação na interação professor-aluno e aluno-aluno, desenvolvimento da autonomia dos alunos, flexibilidade, dinamicidade e portabilidade possibilitada pelos dispositivos móveis (LEITE, 2014). Este mesmo autor ao estudar M-Learning no ensino de química, indica que

Os professores podem através do m-learning fornecer aos alunos conteúdos a qualquer hora, estes podem acessar os conteúdos de química quando necessário, facilitando aos mesmos uma aprendizagem pela comodidade e rapidez de acesso a informação, por se 
tratar de um dispositivo pessoal com grande acolhimento e por estar sempre a "mão" (LEITE, 2014, p. 59).

Como já dito anteriormente, a facilidade de comunicação e o acesso à informação proporcionada pelas TICS modificou a rotina das pessoas. Um dos aplicativos que mais ganhou espaço no dia a dia dos alunos é o WhatsApp. De acordo com Smith (2015 apud KAIESKY et al., 2015, p. 4) "o WhatsApp totalizou 800 milhões de usuários, em 2015, com uma média de 1 milhão de novos usuários por dia, chegando a um volume de 30 bilhões de mensagens enviadas diariamente". Sua inserção no ambiente escolar é bastante controversa, mas alguns estudos já buscam compreender o papel deste aplicativo no contexto escolar (KAIESKY et al., 2015), até mesmo para desmistificar a sua proibição em sala de aula. Alencar et al. (2015), por exemplo, apresentam em sua pesquisa uma experiência com o uso do aplicativo WhatsApp com discentes e docentes do ensino superior, concluindo que

[...] os alunos utilizam constantemente o Whatsapp, dessa maneira ele torna-se um grande facilitador quando se necessitam de uma ferramenta para avisos, compartilhamento de informações e um esclarecedor de dúvidas, tanto por parte dos professores, da instituição ou do aluno. Nesse contexto o Whatsapp é uma ferramenta rápida e eficaz para comunicação entre todas as partes do cenário educacional (ALENCAR et al., 2015, p. 789)

Para além de viabilizar a comunicação entre professores e alunos, o WhatsApp, possibilita que se estabeleçam laços de afetividade entre eles. As interações virtuais, sobretudo em momentos extraclasse, possibilitam um ambiente rico de trocas de conhecimentos e discussões entre professores e alunos, o que permite que a aprendizagem seja constante acontecendo também em espaços não formais de educação, característica básica do M-Learning.

Alencar et al. (2015, p. 789) indica que "o WhatsApp pode ser palco de debates, produção textual e aulas colaborativas, podendo assim ser um grande aliado quando se trata de educação à distância". Embora alguns ainda não estejam adaptados a essa nova forma de trabalhar em sua prática pedagógica, acreditamos que as facilidades do uso do M-Learning e mais especificamente do aplicativo WhatsApp, sejam de grande importância para os docentes e alunos. Ações dos professores em sintonia com as diretrizes escolares, conduziria os alunos a investirem no uso de habilidades que eles já dominam, para que se produzam novas utilidades, mas que não fuja dos objetivos educacionais. Perspectivas como essa, superam também a difícil tarefa de aquisição de insumos tecnológicos para executar as mais variadas TICs. Em muitas escolas, os equipamentos disponíveis ao corpo docente são precários e se encontram em estado de deterioração ou sem acesso à internet.

Contudo, para que ocorram práticas pedagógicas inovadoras, em especial diante desse cenário tecnológico que se impõe aos professores, é necessário de antemão que eles estejam dispostos a aprender a lidar e trabalhar a favor dessas tecnologias, sabendo aproveitar o que há de melhor nelas com fins educacionais.

\section{Metodologia}


Lançamos nessa parte do artigo algumas considerações metodológicas sobre pesquisas empíricas desenvolvidas nos anos de 2016 e 2017 e que permitiram conhecer e discutir a postura dos professores de Ciências e Biologia diante das TICs e do WhatsApp para fins educacionais. Estas pesquisas foram realizadas durante o desenvolvimento de dois Trabalhos de Conclusão de Curso em Biologia licenciatura no estado de Sergipe.

O estudo realizado em 2016 possuía uma abordagem qualitativa, tratando-se de um estudo preliminar com quatro professores das cidades de Tobias Barreto - SE e Rio Real - BA. Seu objetivo geral foi analisar como os recursos didáticos, e em especial as TICs contribuem para o ensino de Ciências e Biologia. Na ocasião da coleta de dados foi utilizada a entrevista semiestruturada a partir de um roteiro com dez questões gerais sobre recursos didáticos e TICs. A pesquisa de 2017 deu continuidade a este trabalho, e utilizando uma abordagem qualiquantitativa, enfatizou aspectos mais específicos das TICs, como o uso do WhatsApp para fins educacionais. Para coleta de dados da referida pesquisa foi utilizado um questionário online com 17 questões (abertas e fechadas) cadastrado no Google Formulários direcionado à professores da área de Ciências e Biologia. A divulgação do questionário foi de extrema importância para a coleta de dados que foi realizada totalmente online. Ao findar de um mês foram obtidos 38 questionários respondidos por professores principalmente dos Estados de Sergipe e da Bahia.

Enfatizamos que diante da extensão dos resultados destas pesquisas, serão discutidas neste artigo dados de natureza qualitativa e quantitativa, que nos permitiram compreender a posição dos professores diante das TICs e do Whatsapp. Assim, apresentamos nas sessões a seguir algumas das falas e respostas de professores de ciências e biologia, discutindo suas concepções acerca das TICs, quais delas estão mais presentes na sala de aula e em que situações elas são usadas. Serão destacados também os temas/conteúdos de Ciências e Biologia mais favorecidos pelo uso destas tecnologias e algumas das experiências dos professores com o WhatsApp no ensino de Ciências e Biologia.

\section{Resultados e Discussão}

Para os professores de nossas pesquisas, os recursos didáticos são usados para facilitar a aprendizagem e compreensão dos conteúdos. Eles afirmaram também que os recursos podem ser usados para introduzir as aulas e deixá-las diferentes. Os recursos listados pelos professores foram: livro didático, computadores, Datashow, quadro branco, pincel atômico e televisão. Destes, os mais utilizados por eles é o livro didático. Para Cicillini (1998) a situação das escolas, bastante precarizadas, faz com que em muitas delas o livro seja a principal e única opção que o professor pode utilizar como recurso que auxilie suas aulas. Percebe-se que a inserção das TICs enquanto um recurso didático ainda é incipiente, corroborando com Carneiro, Santos e Mól (2005) ao afirmar que "apesar dos avanços tecnológicos da enorme variedade de materiais curriculares, atualmente disponíveis no mercado, o livro didático continua sendo o recurso mais utilizado no ensino de ciências".

Quanto à utilização das TICs e sobre a sua experiência com esse tipo de recurso, os professores responderam que tiveram boas e satisfatórias experiências. Porém, apesar de 
ressaltar os aspectos positivos do uso das TICs em sala, alguns professores confessaram ter dificuldades em manusear tecnologias.

Professora 03: "[...] de ponto de partida eu não sabia utilizar o Data show, quando eu entrei na sala foi um choque porque eu não estava preparada".

Ressaltamos aqui, a importância da boa formação docente. É preciso preparar o futuro professor para saber lidar com variados recursos, em prol de um ensino mais dinâmico e uma aprendizagem efetiva. Para Mercado (2002) os cursos de formação também esbarram em dificuldades semelhantes às encontradas na escola básica: falta de investimento em equipamento tecnológico, dificuldade dos formadores em superar preconceitos e a rejeição das tecnologias, mantendo uma formação tradicionalista. Contudo, essa realidade parece estar mudando. É o que aponta alguns dos dados empíricos de nossas pesquisas, em que 65,3\% dos professores tiveram contato com TICs durante sua formação inicial ou continuada. O cenário tecnológico atual pressiona os professores a inovarem em suas práticas, sobretudo diante da velocidade com que as informações chegam aos seus alunos. Essa mesma necessidade acaba por se refletir nos cursos de licenciatura, que já incluem em seus cursos algumas disciplinas com enfoque para as TICs, desenvolvem-se pesquisas e promovem discussões sobre o papel das TICs no ensino.

Alguns professores compreendem as TICs enquanto uma prática de ensino, evidenciando seu papel nas metodologias de ensino, tal qual ilustra as respostas abaixo:

Professor 12: "As TIC podem ser consideradas como uma metodologia de ensino".

Professor 15: "Uma prática pedagógica entrelaçada à aprendizagem, pois é cheia de significados para os discentes".

Para esses professores, as TICs parecem ter um papel maior do que o atribuído aos recursos, sendo centrais no processo de ensino-aprendizagem. Contudo, Souza (2007) afirma que os recursos possuem suas limitações e que não podem, nem devem ser encarados como "salvadores da pátria". Nesse sentido, a concepção dos professores parece se aproximar do que Souza (2007) chama de "inversão didática". Ele afirma ainda que "isso acontece quando o material utilizado passa a ser visto como algo por si mesmo e não como instrumento que auxilia o processo de ensino e de aprendizagem" (SOUZA, 2007, p. 113).

Pelas respostas dos professores, é perceptível a esperança que eles depositam nas novas tecnologias para o desenvolvimento de aulas mais atrativas. Assim, as TICs se configuram como uma das formas de aproximar a escola do mundo digital, como visto na fala do professor quando define o que são TICs.

Professor 11: "São práticas que envolvem tecnologias com objetivo de complementar o processo de ensino e aprendizagem, beneficiando-se de ferramentas mais atrativas ao aluno no contexto atual que vivemos em relação a computadores, celulares, tablets e outros".

Para Júnior, Albuquerque e Coutinho (2016, p. 70), "o aluno está cada vez mais digital e inserido em uma cultura interativa e participativa, a qual pede novas maneiras de ensinar e novas formas de aprender". Rodrigues afirma ainda que os "modelos educacionais que rompem com os métodos convencionais de ensino têm se tornado mais plausíveis a partir de 
transformações causadas pelas TICs e [...], que, de certa forma, ajudam a manter os alunos interessados no que os professores têm a dizer $(2015$, p. 2)."

O uso das TICs na educação ainda está ligado à questão da eficácia na comunicação professor-aluno. De acordo com Rangel (2005, p. 13), "seja qual for a metodologia, não prescinde da comunicação e, ao contrário, depende dela para que a aprendizagem se realize". Os professores pesquisados usam as TICs como uma possibilidade de viabilizar a comunicação entre ele e seus alunos, sobretudo com vista a estreitar as relações interpessoais. Os autores Pereira, Pereira e Alves (2015, p. 37), em estudos semelhantes ao nosso, indicam que "embora outros usos sejam citados, fica bastante claro a possibilidade da ampliação da relação interpessoal com alunos, se sobrepondo a usos que poderiam ser mais clássicos em educação: o uso de mídias e a distribuição de conteúdo". Ponte (2000) também indica esta possibilidade, afirmando que esta relação é profundamente alterada pelas TICs, sobretudo para os professores que as utilizam mais ativamente.

Quando solicitado que indicassem quais as TICs eles já haviam utilizado em suas aulas, apenas 2,6\% indicaram não as usar. Dentre as TICs listadas, o Whatsapp aparece como o mais utilizado pelos professores em sua prática, totalizando $71,1 \%$ dos respondentes. E-mail, plataformas de pesquisa, compartilhamento de vídeos, filmes e animações aparecem também com valores expressivos (entre $68,4 \%$ e $60,5 \%$ ). As redes sociais aparecem com 55,3\% de frequência, indicando que os professores não as priorizam tanto quanto as ferramentas citadas acima. De acordo com Jesus et al. $(2014$, p. 6):

As redes sociais ainda não são vistas com bons olhos por todos os professores. Deve-se considerar que qualquer ferramenta que venha auxiliar na prática docente precisa ser bem compreendida por quem vai aplicá-la, sobretudo quanto ao conhecimento que está usando. Muitas vezes, a falta de conhecimento sobre os potenciais educativos das redes sociais faz com que muitos professores pensem que esses ambientes não sejam próprios.

Os dados para essa questão são apresentados detalhadamente no gráfico abaixo e mostram um panorama geral das TICs mais utilizadas pelos professores em suas aulas.

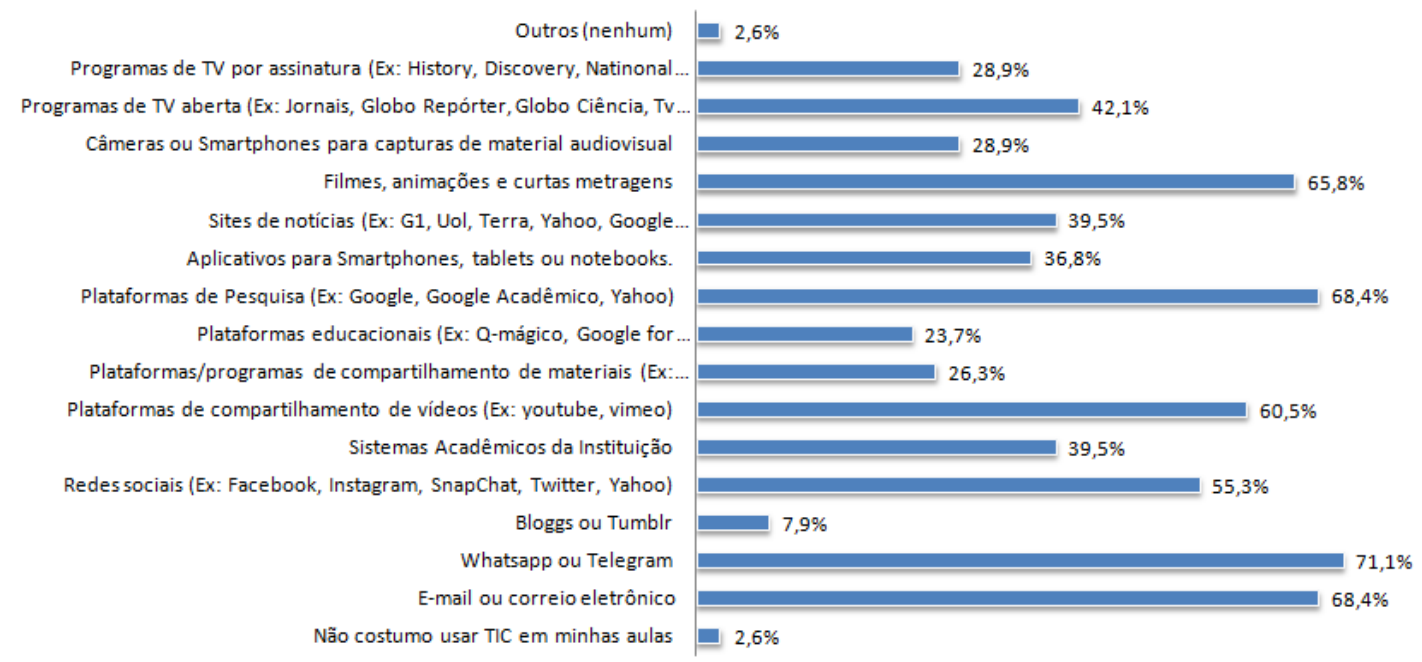

Figura 1 - TICs utilizadas pelos professores em suas aulas. (Fonte: dados da pesquisa) 
Buscando compreender como estes professores utilizavam as TICs em sua prática, verificamos que $78,9 \%$ deles afirmam que fazem uso das TICs para desenvolver suas aulas e se comunicarem com seus alunos. Em posição oposta, 10,5\% afirmam não utilizarem TICs para desenvolver suas aulas. Esse último resultado, contrasta com o exposto na figura 1, no qual apenas 2,6\% dos professores indicam não utilizar as TICs. Acreditamos que esse resultado seja fruto de uma dificuldade de significar as TICs dentro de suas práticas, ou de defini-las como evidenciamos nas discussões anteriores. Por fim, 5,3\% indicaram usá-las para desenvolver aulas e em igual valor afirmaram que as usavam apenas para se comunicarem com alunos, colegas de trabalho e superiores.

\section{Os conteúdos de ciências e biologia e as TICs}

A maioria dos respondentes traz a seu favor o uso das TICs em vários conteúdos. É possível notar a enorme potencialidade das TICs enquanto um recurso para o ensino, podendo contemplar todos os conteúdos do currículo escolar. Vasconcelos e Nascimento (2015, p. 141) afirmam que [...] "os recursos das TIC presentes na escola superam a perspectiva de facilitadores das rotinas de ensinar e aprender, pois têm a possibilidade de organizar um novo ambiente de aprendizagem com um ensino inovador". Contudo, alguns conteúdos ganham destaque, são eles: Citologia, Anatomia Humana, Botânica, Microbiologia, Bioquímica, Genética e Histologia.

Professor 17: "Especialmente, os mais distantes da realidade dos alunos, por exemplo, citologia microbiologia."

Professor 26: "Acredito naqueles conteúdos em que apresentam elementos que não podem ser observados a olho nu, como: Citologia, Bioquímica Genética Microbiologia Histologia entre outros".

Algumas iniciativas que buscam integrar ensino de áreas específicas, como a Botânica, ao uso das TICs, já têm sido tomadas em diversos locais do país. É o caso da pesquisa-ação desenvolvida por Sorge et al. (2014) em que foram realizadas aulas de botânica utilizando herbários digitais. Oliveira (2013) em pesquisa semelhante a nossa, constatou que os professores citam os conteúdos de Fisiologia, Citologia, Zoologia e Ecologia como os que mais necessitam que recursos audiovisuais. Carlan, Sepel e Loreto (2013, p. 347) indicam que "Inserir diferentes recursos didáticos na prática pedagógica do professor pode ser uma boa alternativa para ensinar conceitos complexos e abstratos como os relacionados ao conteúdo de Biologia Celular".

Diante da complexidade dos conteúdos abordados na disciplina de Biologia é extremamente positivo que os professores lancem mão de ferramentas diversificadas para o entendimento dos assuntos, em especial aqueles nos quais os alunos não possuem contato direto ou não conseguem visualizar a olho nu, como é o caso de Citologia e Botânica.

\section{As experiências dos professores com o Whatsapp}

Pedimos aos professores que compartilhassem conosco algumas das suas experiências educacionais com o aplicativo WhatsApp, revelando momentos em que o aplicativo possibilitou 
maior afetividade entre professores e alunos. Leite (2012, p. 356) afirma que "a mediação pedagógica também é de natureza afetiva e, dependendo da forma como é desenvolvida, produz impactos afetivos, positivos ou negativos, na relação que se estabelece entre os alunos e os diversos conteúdos escolares desenvolvidos". Nesse sentido, os conteúdos tornam-se mais atraentes e o interesse dos alunos aumenta conforme os laços de afetividade se consolidam entre eles e seus professores. Esses aspectos podem ser constatados pelas respostas abaixo:

Professor 20: "Ganhei a confiança dos meus alunos com o uso do WhatsApp. Eles sempre acham que os professores são superiores a eles e com essa proximidade há uma quebra desse paradigma".

O aplicativo também tem se tornado um grande facilitador da comunicação entre alunos e professores, principalmente como complemento no processo de ensino-aprendizagem, como vemos na resposta abaixo:

Professor 17: "Em vésperas de provas, os alunos já me contactaram para sanar dúvidas que ainda restavam sobre um determinado conteúdo, enquanto revisavam em suas casas."

As experiências dos professores evidenciam um dos usos mais comuns para o WhatsApp: a possibilidade de comunicação rápida, quase que instantânea, aproveitando disto para sanar as dúvidas que restam acerca dos conteúdos enquanto estudam em suas casas. Estudos de Alencar et al. $(2015$, p. 789$)$ indicam que o WhatsApp se torna um grande facilitador quando se necessita de uma ferramenta para avisos, compartilhamento de informações e um esclarecedor de dúvidas, tanto por parte dos professores, da instituição ou do aluno.

Foi evidenciado também que algumas das experiências dos professores envolviam a criação de grupos do WhatsApp que proporcionaram desenvolvimentos de projetos paralelos às aulas e o compartilhamento de materiais.

Professor 31: "Tenho um grupo com meus alunos no qual uso para lembrá-los das lições a ser estudadas, compartilhar documentos que contribuam no estudo e no desenvolvimento de sua aprendizagem..."

Junior, Albuquerque e Coutinho (2015) indicam como uma vantagem do WhatsApp a possibilidade de compartilhar materiais de diversas naturezas. Os autores Kaieski, Grings e Fetter $(2015$, p. 5$)$ ao discutirem as possibilidades de uso do aplicativo indicaram ao final de sua pesquisa que o "WhatsApp gerou impactos positivos na participação dos alunos, promovendo a aprendizagem socioconstrutivista através de discussões espontâneas, aumentando a autoconfiança do estudante para se envolver nas discussões e melhorando o compartilhamento do conhecimento".

Através destes relatos, percebemos que os docentes já consideram as TICs no ensino. As experiências compartilham boas perspectivas de aprendizagem em Ciências e Biologia. Esse fato indica um esforço significativo dos docentes com os variados recursos, em prol de um ensino mais dinâmico e significativo para todos os que estão envolvidos nesse novo cenário educativo, cada vez mais tecnológico. 


\section{Considerações Finais}

Diante do exposto, podemos considerar que as TICs podem promover o desenvolvimento do ensino de Ciências e Biologia e abrir um leque de possibilidades que trazem desafios inovadores na aprendizagem. Por entender que o WhatsApp é um aplicativo muito usado pelos jovens e que pode ser considerado uma ferramenta de comunicação educacional, podemos afirmar que existe possibilidades de romper as fronteiras na expansão de conhecimento através do referido aplicativo e pelas as TICS.

A educação é um processo contínuo e o professor deve estar atento às mudanças, buscando estratégias de ensino para aprimorar as suas aulas. $O$ professor não deve ignorar as TICs, e de fato ele não assume essa postura, mas deve saber introduzi-las em sala de aula para facilitar o processo de ensino-aprendizagem.

Por fim, consideramos importante o laboratório de informática e de Biologia nas instituições afim de modificar as aulas tradicionais e rotineiras, em aulas mais atrativas e dinâmicas para que despertem o interesse dos alunos. O ensino de Ciências e Biologia não pode se limitar apenas a exposição oral, precisa ser mais explorado e o uso das TICs pode facilitar a compreensão do conteúdo científico.

\section{Referências}

ALENCAR, G. PESSOA, M. dos S. SANTOS, A. K. de F. S. CARVALHO, S. LIMA, H. A. de B.

WhatsApp como ferramenta de apoio ao ensino. In: IV Congresso Brasileiro de Informática na Educação. Anais eletrônico... Maceió: Universidade Federal de Alagoras, 2015.

BATISTA, S. C. F.; BARCELOS, G. T. Análise do uso do celular no contexto educacional. RENOTE, v. 11, n. 1, 2013.

CARLAN, F. de A.; SEPEL, L. M. N.; LORETO, E. L. da S. Explorando diferentes recursos didáticos no Ensino Fundamental: uma proposta para o ensino de célula. Acta Scientiae, v. 15, n. 2, p. 338-353, 2013. p. 338-353.

CARNEIRO, M. H. da S.; SANTOS, W. L. P dos; MÓL, G. de S. Livro didático inovador e professores: uma tensão a ser vencida. Ensaio Pesquisa em Educação em Ciências, v. 7, n. 2, 2008. p. $119-130$.

CICILLINI, G. A.; Ensino de biologia: O livro didático e a prática pedagógica dos professores no Ensino Médio. Ensino em Revista, v. 6, n.1, jun., 1998. p. 29-37.

JUNIOR, J. B. B.; ALBUQUeRQUE, O. C. P; COUTINHO, C. P. WhatsApp e suas Aplicações na Educação: uma revisão sistemática da Literatura. Revista EducaOnline, v. 10, n. 2, 2016. p. 6787.

KAIESKI, N. GRINGS, J. A. FETTER, S. A. Um estudo sobre as possibilidades pedagógicas de utilização do WhatsApp. RENOTE, v. 13, n. 2, 2016. p. 1-10.

LEITE, S. A. da S. Afetividade nas práticas pedagógicas. Temas em psicologia, v. 20, n. 2, 2012. p. 355-368. 
LEITE, B. S. M-Learning: o uso de dispositivos móveis como ferramenta didática no Ensino de Química. Revista Brasileira de Informática na Educação, v. 22, n. 3, 2014. p. 55-68.

MARTINHO, T; POMBO, L. Potencialidades das TIC no ensino das Ciências Naturais - um estudo de caso. Revista Electrônica de Enseñanza de las Ciências, v. 8, n. 2, 2009.

MERCADO, L. P. L.; Formação docente e novas tecnologias. In: MERCADO, L. P. L. (Org.). Novas tecnologias na educação: reflexões sobre a prática. Maceió: EDUFAL, 2002. p.11-28.

OLIVEIRA, T. T.; Uso de TICs no ensino de Biologia: um olhar docente. 30f. Monografia (Especialização). Universidade Tecnológica do Paraná, Medianeira, 2013.

PEREIRA, P. C.; PEREIRA, R. S. ALVES, J. da C. Ambientes virtuais e mídias de comunicação, abordando a explosão das mídias na sociedade da informação e seu impacto na aprendizagem o uso do WhatsApp como plataforma de m-learning. Revista Mosaico, v. 6, n. 1, 2015. p. 29-41.

PIERRE, Levy. Cibercultura. São Paulo, 1. ed.Ed.34,1999.

PONTE, J. P. da Tecnologias da Informação e Comunicação: que desafios? Revista Iberoamericana de Educación, n. 24, 2000. p. 63-90.

QUARTIERO, E. M.; As tecnologias da Informação e Comunicação e a Educação. Revista Brasileira de Informática na Educação. n. 4, 1999. Não paginado.

RANGEL, M. Comunicação e Ensino-aprendizagem: a dinamização essencial da sala de aula. In: RANGEL, M. Métodos de Ensino para aprendizagem e dinamização das aulas. Coleção Magistério: Formação e Trabalho Pedagógico. São Paulo, SP: Papirus, 2005.

RIBEIRO, E. N. MENDONÇA, G. A. de A.; MENDONÇA, A. F. A importância dos ambientes virtuais de aprendizagem na busca de novos domínios da EAD. In: 13을 Congresso Internacional de Educação a Distância. Anais eletrônico... Curitiba, Brasil. 2007.

RODRIGUES, T. A utilização do aplicativo WhatsApp por professores em suas práticas pedagógicas. In: 6อSimpósio Hipertexto e Tecnologias na Educação,2Colóquio Internacional de Educação com Tecnologias. Anais Eletrônicos..., UFPR, 2015.

SORGE, C. J.; ALBA, T. M.; GULLICH, R. I da C.; SIVERIS, S. C. W.; Construindo herbários digitais no ensino médio politécnico: oficina de botânica. Revista SBEnBio, n. 7, out. 2014. p. 1147-1154.

SOUZA, S. E. O Uso de Recursos Didáticos no Ensino Escolar. In: I Encontro de Pesquisa em Educação, IV Jornada de Prática de Ensino, XIII Semana de Pedagogia da UEM: "Infância e Práticas Educativas". Arq Mudi. Maringá: UEM, 2007.

VASCONCELOS, C. A.; NASCIMENTO, E. dos S. Tecnologias da Informação e Comunicação (TIC): educação e interatividade. In: SOUZA, D. do N.; SILVA, V. A. da (Org.). A questão do sentido em pesquisas em ensino de Ciências e Matemática: uma homenagem a Bernard Charlot. São Paulo: Editora Livraria da Física, p. 137-156. 2015.

VIANNA, D. M.; ARAÚJO, R. S.; Buscando Elementos na Internet para uma Nova Proposta Pedagógica. In: CARVALHO, A. M. P. de (Org.). Ensino de Ciências: unindo pesquisa e a prática. São Paulo, SP: Pioneira, 2006. p.135-154. 